\title{
EVALUATION OF THE HYGIENIC QUALITY OF RAW MILK BASED ON THE PRESENCE OF BIFIDOBACTERIA SPP. AS AN INDICATOR OF FAECAL CONTAMINATION IN ASSIUT CITY
}

MARWA M.N. EL-GENDI and LAMIAA M.T. ALI

Animal Health Research Institute, Assiut Lab.

\section{ABSTRACT}

Received at: $25 / 6 / 2012$

This study aimed to evaluate the hygienic quality of raw buffalo's and cow's milk sold in Assiut city, Egypt; based on the presence of Bifidobacterium spp. as indicator of fecal contamination. Bifidobacteria species forms one of the most important groups of flora in the intestine of both human and animals. Speciesisolated in humans are different from those isolated in animals. It should therefore be possible to determine contamination origin (human or animal). Seventy samples of raw buffalo's and cow's milk (35 samples from each) were collected randomly from; some dairy farms, individual cases of dairy buffaloes

Accepted: 26/8/2012 and cows and dairy shops in Assiut city, all samples were examined for the presence of Bifidobacteria spp. Each sample was firstly inoculated in MRS \& BHIMup, then two different culture media (CMup \& Bifidobacterium media (BFM)) were used for isolation and identification of Bifidobacterium. Bifidobacterium spp. was identified in $65.71 \%$ (23samples) and 51.42\% (18 samples) of raw buffalo's and cow's milk, respectively. Isolates were identified and differentiated and the findings revealed that raw cow's milk harboured B. dentium in $61.11 \%, B$. suis in $27.77 \%$ and B. bifidum in only 2 samples (11, $11 \%$ ) of examined samples. B. dentium, B. suis and B. bifidumwere found contaminating $47.82,39.13$ and $13.04 \%$ of examined raw buffalo's milk samples. Presence of $B$. bifidum revealed contamination of raw cow's and buffalo's milk with human stool (adult and infants); however isolates of $B$. suis indicated the contamination with feces of piglets. Also the detection of $B$. dentium in examined samples showed that there is contamination with human discharges coming from mouth suffering dental caries; human abscesses, vaginal discharges and feces. These organisms considered potentially pathogenic and have hazards effect on human health.

Key words: Bifidobacteria, raw Buffalo's milk, raw Cow's milk.

\section{INTRODUCTION}

The local dairy commodity chain, from farm to retail sites is informal and often escapes monitoring of quality. In addition, most stakeholders lack knowledge on hygiene and sanitary aspects of their production, which can result in poor production standards and contamination of local raw milk. Bifidobacteria are well known for their beneficial effects on health and are used as probiotics in certain food and pharmaceutical products. Since they constitute one of the most important bacteria group in human and animal digestive tract, they were recently considered as fecal contamination indicators in raw milk dairy products. Moreover, the Bifidobacteria spp. isolated in humans are different from that isolated from animals (Delcenserie, et al., 2005). Fecal contamination of raw milk in farms has been shown by the detection of the same and most frequent Bifidobacterium spp. in milk as in cow's dung. Raw milk can be assumed to be the first critical point in an HACCP analysis of the raw milk cheese industry, but a follow-up of contamination during the cheesemaking process is also of interest. The standard in Europe for fecal contamination control of raw milk cheese is Escherichia coli (Beerens et al., 2000).

The general objective is to define a new standard, using the Bifidobacteria (genus Bifidobacterium) as indicator organisms in order to point out unsatisfactory hygienic conditions of raw material and food products. These new indicators will be applied on raw milk and cheese made from it, as the quality of which depends on the hygiene of milking, the farm environment and the hygiene along the cheese production chain. Also meat and meat products in which Bifidobacteria will indicate hygienic shortcomings during slaughter, cutting and debuting as well as retail trade. Good hygienic practices must lead to the elimination of all bacterial hazards such as Listeria, E. coli (Entero hemorrhagic E.coli (EHEC)) or Salmonella spp. The knowledge of the Bifidobacterium spp. that contaminate raw milk, cheese made with raw milk, meat and meat products will point out the sites from which the contamination 
derives the development of a fast, sensitive and generally applicable technique will enable industries to detect Bifidobacteria during processing and to take corrective actions immediately. Due to their intestinal ecology, milk is not the natural environment of Bifidobacteria. Their presence in milk is a sign of fecal contamination (Delcenserie et al., 2005) and can therefore serve as a marker of the level of hygiene in the production chain (Beerens et al., 2000). In addition, the species characterization and assessment of antibacterial potential could lead to its determination in milk, as a selection method of food safety strains. Moreover, an advantage in using Bifidobacteria instead of other fecal contamination indicators is the host specificity of Bifidobacterium spp in human or animal (Gavini and Beerens, 1999). Raw milk collected with proper hygiene should not contain Bifidobacteria. In fact, the presence of Bifidobacteria in raw milk indicates fecal contamination and poor farm hygiene (Beerens et al., 2000; Beerens and Neut, 2005). This bacterium has been recently proposed as a fecal indicator in water (Lynch et al., 2002; Gilpin et al., 2003 and Nebra et al., 2003) and in meat and raw milk samples (Beerens, 1998; Gavini and Beerens, 1999; Beerens et al., 2000).

Bifdobacteria have been suggested as among the more promising alternative indicators of faecal pollution. They are present in faeces at levels 10:100 times greater than coliforms and, due to their anaerobic nature, fastidious growth requirements and inability to grow below $20^{\circ} \mathrm{C}$, they are unlikely to multiply outside the intestinal tract (Mara and Oragui, 1983).

Since most bifidobacterial strains used in dairy products are common members of the human intestinal microbiota, they may behave as opportunistic pathogens, like other commensal bacteria (Saarela et al., 2002). Some commensal Bifidobacteria have been connected with certain dental infections, pulmonary infections, bacteremia, abscesses and bloodstream infections (Green, 1978; Gasser, 1994; Saarela et al., 2002). In infants aged 2 to 16 months, Brook (1996) described a prevalence of 57 Bifidobacterium isolates among 2033 specimens originating from chronic otitis media, abscesses, peritonitis, aspiration pneumonia and paronychia. In most cases, the non-probiotic $B$. dentium (formerly $B$. eriksonii) was implicated, this is the only bifidobacterial species classified as a dental pathogen. A few cases also implicated $B$. adolescentis, which has been recovered purefrom otitis media (Brook, 1996). Despite these few cases, the recovery of Bifidobacteria in clinical infections is very rare in comparison to other commensals (Borriello et al., 2003). The most commonly used faecal indicator organisms, faecal coliforms, including E. coli, denote faecal pollution but not whether it is of human or animal origin. As a consequence, alternative indicators of faecal pollution better able to identify the faecal source have been suggested, including
Bacteriodes spp., phages of Bacteroides fragilis, F-RNA phage, Rhodococcus coprophilus, Bifdobacteria, and various chemical indicators (Sinton et al., 1998).

Bifidobacteria, previously known as Bacillus bifidus, are a group of microorganisms that were classified into 29 different species in the 9th Edition of Bergey's Manual of Systematic Bacteriology (Scardovi, 1986). Nowadays, there are more than 33 species that were identified from the genus Bifidobacterium using recent molecular and biochemical methods of which 12 have been associated with the human gastrointestinal tract (Ventura et al., 2004).

Bifidobacteria are Gram-positive, non-motile, and non-spore-forming bacteria. They are part of normal intestinal microbiota in humans and animals, and are generally non-pathogenic. They were considered to be anaerobic (Simpson et al., 2004a).

Present study has been carried out to evaluate the hygienic quality of raw buffalo's and cow's milk sold in Assiut city based on the presence of Bifidobacterium spp. as indicators of faecal contamination.

\section{MATERIALS and METHODS}

1- Raw milk samples: 70 samples of raw buffalo's and cow's milk (35 samples from each) were collected randomly from; some dairy farms, individual cases of dairy buffaloes and cows and dairy shops in Assiut city. Samples collected directly after milking and transported to the microbiological laboratory for examination. Each sample was kept in a sterile bag containing peptone water $(0.1 \%)$ to which we added $0.25 \%$ L-cysteine.

2- Culture media: Numerous culture-based methods for Bifidobacteria detection, isolation and typing have been described. Culturing of Bifidobacterium and its evolution within gastrointestinal flora (human or animal) was carried out according to Martineau (1999); Rada and Petr (2000) and Petr and Rada (2001). MRS \& BHIMup and two different culture media (CMup \& Bifidobacterium media (BFM)) were used for isolation and identification of Bifidobacterium spp.

\section{1- Bifidobacteria isolation:}

Two culture-based methods were used to detect Bifidobacteria spp. which comprised enrichment and isolation steps. The first method was done by inoculating $2 \mathrm{~g}$ of each sample of raw milk in $18 \mathrm{ml}$ MRS broth as enrichment medium. $500 \mathrm{mg} / 1$ of Lcysteine hydrochloride has been added to MRS broth to reduce ox-reduction (ox-re) potential. The inoculated media were incubated anaerobically at $37 \mathrm{C}^{\circ}$ for $48 \mathrm{hrs}$. In order to obtain single colonies, the cultured mMRS were streaked on the surface of 
Bifidobacterium media (BFM) and incubated anaerobically at $37 \mathrm{C}^{\circ}$ for $72 \mathrm{hrs}$.

The second method was carried outaccording toisolation procedures described by Beerens (1998) and culture-based methods modified by Delcenserie et al. (2005). One millileter of each samples was transferred into $9 \mathrm{ml}$ of enrichment medium BHMup [BHI, $37 \mathrm{~g} / \mathrm{l}$ (oxoid, England), $5 \mathrm{ml} / 1$ of propionic acid, $0.5 \mathrm{~g} / 1$ Fe-citrate, $0.5 \mathrm{~g} / 1$ cystein chlorhydrate, 5 $\mathrm{g} / \mathrm{l}$ yeast extract and $2 \mathrm{~g} / \mathrm{l}$ agar]. Mupirocin, 80 $\mathrm{mg} / \mathrm{lwas}$ added before the useof the medium. The final $\mathrm{pH}$ was 5.0 and obtained with the addition of 1 $\mathrm{mol} / \mathrm{lNaOH}$ solution. Tubes were incubated for $48 \mathrm{hrs}$ at $37^{\circ} \mathrm{C}$ in Jars with anaerobic conditions. From each enrichment culture, $0.1 \mathrm{ml}$ was spread on isolation medium CMup (Columbia blood agar, $0.5 \mathrm{~g} / \mathrm{l}, \mathrm{Fe}-$ citrate, $5 \mathrm{~g} / 1$ glucose and $0.5 \mathrm{~g} /$ lcystein chlorhydrate). Mupirocin was added $(50 \mathrm{mg} / \mathrm{l})$ before the use of the medium. Plates were incubated anaerobically at $37^{\circ} \mathrm{C}$ for $72 \mathrm{hrs}$. Samples which have grown on both of the two selective media considered positive while samples which have grown on only one media, have been discarded. Colonies were rounded, blue and approximately $2 \mathrm{~mm}$ in diameter a few minutes after removal from anaerobic condition.

\section{2- Identification of isolates:}

a- Phenotypic characterization: Each strain isolated was cultured on MRS agar (MRS agar to which we added, $0.25 \%$ L-cysteine). Inoculated plates were incubated anaerobically at $37^{\circ} \mathrm{C}$ for 24 to $48 \mathrm{~h}$. Isolates observed were stained with methylene blue and examined microscopically $(1000 \mathrm{x})$. Only strains with the "Y" phenotypic form were selected for the identification (Rasic and Kurman, 1983).

All strains were initially submitted to Gram staining, catalase and spore formation test. Colonies and cells morphology characteristics on TPY containing $0.2 \%$ cysteine-HCl, MRS and M17 agar were also examined. Gas production from glucose was determined in MRS broth containing inverted Durham (Grill et al., 2000). Citrate utilization, in the presence of carbohydrates, was performed on the media of Kihal et al. (1996).

\section{b- Carbohydrate fermentation}

The carbohydrates fermentation was determined on TPY broth containing bromocresol purple $(0.04 \mathrm{~g} / \mathrm{l})$ as a $\mathrm{pH}$ indicator, and supplemented with $1 \%$ of the following carbohydrates: lactose, sucrose, xylose, arabinose, sorbitol, fructose, galactose, mannose, cellobiose, raffinose, melizitose and melibiose. To ensure anaerobic conditions, each tube was supplemented with two drops of sterile liquid paraffin after inoculation (Samelis et al., 1994; Saidi et al., 2002). The results obtained for morphological, physiological and biochemical tests were compared with those in standard texts for identification
(Scardovi, 1986; Miyake et al., 1998, Ingrassia et al., 2001) and the isolates assigned to appropriate species. The isolates belonging to the genus Bifidobacterium were identified to species level using sugar fermentation and the profiles were compared with the reference strains in standard texts for identification.

\section{RESULTS}

Bifidobacterium spp. was identified in $65.71 \%$ (23samples) and $51.42 \%$ (18 samples) of raw buffalo's and cow's milk, respectively (Table, 1). Isolates were identified and findings revealed that raw cow's milk samples harbored B.dentium in $61.11 \%$ while B. suis was identified in $27.77 \%$ of examined samples(Table, 2). B. bifidum were isolated from 2 samples $(11.11 \%)$. B. dentium, B. suis and B. bifidum were found contaminating 47.82, 39.13 and 13.04\% of examined raw buffalo's milk (Table, 2).

Table 1: Percentage of positive raw Cow's and Buffalo's milk samples that contain Bifidobacteria spp.

\begin{tabular}{|c|c|c|c|}
\hline \multirow{2}{*}{$\begin{array}{l}\text { Type of } \\
\text { examined } \\
\text { samples }\end{array}$} & \multirow{2}{*}{$\begin{array}{l}\text { No. of } \\
\text { examined } \\
\text { samples }\end{array}$} & \multicolumn{2}{|c|}{$\begin{array}{l}\text { Positive samples for } \\
\text { all isolated } \\
\text { Bifidobacteria spp. }\end{array}$} \\
\hline & & No. & $\%$ \\
\hline $\begin{array}{l}\text { Raw cow's } \\
\text { milk }\end{array}$ & 35 & 18 & $51.42 \%$ \\
\hline $\begin{array}{l}\text { Raw buffalo's } \\
\text { milk }\end{array}$ & 35 & 23 & $65.71 \%$ \\
\hline
\end{tabular}

Table 2: Bifidobacteria spp. isolated from the examined samples of raw cow's and buffalo's milk.

\begin{tabular}{|c|c|c|c|c|}
\hline \multirow{3}{*}{ Bifidobacteria spp. } & \multicolumn{2}{|c|}{ Raw Cow's milk } & \multicolumn{2}{|c|}{$\begin{array}{l}\text { Raw Buffalo's } \\
\text { milk }\end{array}$} \\
\hline & $\begin{array}{l}\text { Positive } \\
\text { sample }\end{array}$ & $\%$ & $\begin{array}{l}\text { Positive } \\
\text { samples }\end{array}$ & $\%$ \\
\hline & No. $=18$ & & No. $=23$ & \\
\hline $\begin{array}{l}\text { Bifidobacterium } \\
\text { dentium }\end{array}$ & 11 & 61.11 & 11 & 47.82 \\
\hline $\begin{array}{l}\text { Bifidobacterium } \\
\text { suis }\end{array}$ & 5 & 27.77 & 9 & 39.13 \\
\hline $\begin{array}{l}\text { Bifidobacterium } \\
\text { bifidum }\end{array}$ & 2 & 11.11 & 3 & 13.02 \\
\hline Total & 18 & 100 & 23 & 100 \\
\hline
\end{tabular}




\section{DISCUSSION}

Presence of $B$. bifidum revealed that raw cow's and buffalo's milk may be contaminated with feces of the human (adult and infants). However, isolation of $B$. suiscould be attributed to pollution with feces of piglets. Also the detection of $B$. dentium in examined samples could be attributed also to contamination with human discharges coming from; mouth suffering dental caries, human abscesses, vaginal discharges and feces. These organisms considered potentially pathogenic and have hazards effect on human health.

Commensal Bifidobacteria (B. dentium) have been connected with certain dental and other infections (Leo et al., 2008). Lynch et al. (2002), Nebra et al. (2003) and Bonjoch et al. (2004) recorded that $B$. adolescentisor $B$. dentiumare indicators of fecal pollution. As these species are dominant in human feces, they will indicate a contamination of human origin (Scardovi, 1986).

Kouamé-Sina et al. (2011) found that isolates belong to five different species of Bifidobacterium were present in $9 \%$ of milk samples. Most of the Bifidobacterium isolated were B. minimum (53\%) and B. pseudolongum sub spp. globosum (24.4\%). The other strains are composed of one strain of B. thermophilum, B. thermacidophilum sub spp. Suis and B. magnum.

The typical habitats of Bifidobacteria are human, warm-blooded animal and honeybee intestinal tract (Scardovi, 1986). Members of genus Bifidobacterium are among the most common microorganisms in the human gut, comprising up to $3 \%$ of the total faecal microflora of adults (Sghir et al., 2000). They are more numerous in the infant gut, where they form up to $91 \%$ of the total microflora in breast-fed babies being supported by bifidogenic factors presented in human milk and up to $75 \%$ in formula-fed infants (Harmsen et al., 2000). Using classical culturing methods it has been found that $B$. adolescentis and $B$. longumare major bifidobacterial species in theintestine of adults (Biavati et al., 1986; Mutai and Tanaka, 1987; Gavini et al., 2001). B.infantis and B. breveare predominant species in the intestinal tract of human infants (Benno et al., 1984; Biavati et al., 1984; Mutai and Tanaka, 1987). In addition, B. bifidum, B. catenulatum, B. pseudocatenulatum, $B$. angulatum, B. gallicum, and $B$. dentium have also been reported to be human intestinal bifidobacteria (Scardovi, 1986). Matsuki et al. (1999) who used for the detection of bifidobacteria in human gut speciesspecific polymerase chain reaction (PCR) reported, that the most common species in the breast-fed infants are $B$. breve, B. infantis, B.longum, and $B$. bifidum. In adult intestinal tracts, the $B$. catenulatum group was the most common taxon, followed by B. longum and B. adolescentis.

In the case of raw milk samples, an enrichment step was necessary because of the possible relatively low levels of bifidobacteria ( 10 to $10^{6} / \mathrm{ml}-1$ ) compared to those in human or animal feces $\left(10^{7}\right.$ to $\left.10^{10} / \mathrm{g}-1\right)$. Beerens (1998) recommended the using at the enrichment step the BHI medium with addition of propionic acid, yeast extract, iron citrate, and at the isolation step, paromomycin as selective agent. However, the high number of lactobacilli that were not inhibited by paromomycin hides bifidobacteria at low dilutions. Rada and Petr (2000) showed that bifidobacteria were resistant to mupirocin when lactobacilli were susceptible. Mupirocin (pseudomonic acid A) was originally isolated from Pseudomonasfluorescens and used as a topical antibiotic (Sutherland et al., 1985). In raw milk samples, addition of mupirocin at the enrichment step can eliminate most of the lactobacilli strains present that could hide Bifidobacteria in raw milk. If some lactobacilli strains were still present after the enrichment step, one might suppose that they would be eliminated during the isolation step by mupirocin, when present. Grand et al. (2003) also used mupirocin as selective agent for detection of Bifidobacteria in probiotic milk products, as did Mikkelsen et al. (2003) in gastrointestinal samples from piglets and Simpson et al. (2004b) in probiotic as animal feed.

Moreover, Rhodes and Kator (1999) enumerated sorbitol-fermenting Bifidobacteria to define human fecal pollution in estuarine watersheds. However, in raw milk cheese, the principal contamination was shown to be of animal origin (Beerens et al., 2000), most likely by cow dung onfarm, since the same species, B. pseudolongum, was isolated from both kinds of samples. Therefore, in food industries, it seems important to define the human or animal origin of the contamination.

The milk contamination by Bifidobacteria is also an indicator of fecal contamination (Beerens et al., 2000) and is due to the lack of hygiene in farms. Its presence on cow's udder reflects environmental contamination with feces of other animals living in farms or in the vicinity. Our results indicated insignificant variation in the prevalence of Bifidobacterium along the dairy production chain. Contamination by Bifidobacterium was present at all stages of milk production. These results indicated fecal contamination at all stages of the production chain, from production to selling point of raw milk. This suggests a lack of sanitary education of farmers and milk vendors. This sanitary education of farmers is important especially on good hygiene practices through simple actions like washing and disinfecting of hands, cow's udders and milking utensils (Bonfoh et al., 2003).

Finally it could be concluded that the hygienic quality of local raw milk was assessed as poor, based on the detection of the Bifidobaterium in raw milk (Therefore the Bifidobaterium isolated in this study are rather an indication of poor hygiene). In order to improve the microbiological quality of local raw milk, fermentation as well as heating is needed to 
inhibit the growth of contamination germs. The safety strategy should be developed, with good hygiene practices related to cleanliness of animals and their environment as well as sanitation of the milking process (milker's hands, milking utensils).

\section{REFERENCES}

Beerens H. (1998): Bifidobacteria as indicators of faecal contamination in meat and meat products: detection, determination of origin and comparison with Escherichia coli. Int. J. Food Microbiol., 40: 203-207.

Beerens, H.; De la Perriere, H.B. and Gravini, F. (2000): Evaluation of the hygienic quality of raw milk based on the presence of Bifidobacteria: the cow as a source of faecal contamination. Int. J. Food Microbiol.,. 54: 163-169.

Beerens, H. and Neut, C. (2005): Usefulness of bifidobacteria for the detection of faecal contamination in milk and cheese. Lait. 85: 33-38.

Benno, Y.; Sawada, K. and Mitsuoka, T. (1984): The intestinal microflora of infants: composition of fecal flora in breast-fed and bottle-fed infants. Microbiol. Immunol. 28: 975-986.

Biavati, B.; Catagnoli, P. and Trovatelli, L.D. (1986): Species of the Bifidobacterium in the feces of human adults. Microbiologica., 9: 39-45.

Biavati, B.; Catagnoli, P.; Crociani, $F$. and Trovatelli, L.D. (1984): Species of the Bifidobacterium in the feces of infants. Microbiologica. 7: 341-345.

Bonfoh, B.; Wasem, A.; Traoré, A.N.; Fané, A.; Spillmann, H.; Simbé, C.F.; Alfaroukh, I.O.; Nicolet, J.; Farah, Z. and Zinsstag, J. (2003): Microbiological quality of cows' milk taken at different intervals from the udder to the selling point in Bamako (Mali). Food Control, 4: 495-500.

Bonjoch, X.; Balleste, E. and Blanch, A. (2004): Multiplex PCR with 16S rRNA gene-targeted primers of Bifidobacterium spp. to identify sources of fecal pollution. Appl. Environ. Microbiol. 70: 3171-3175.

Borriello, S.P.; Hammes, W.P.; Holzapfel, W.; Marteau, P.; Schrezenmeir, J.; Vaara, M. and Valtonen, $V$. (2003): Safety of probiotics that contain lactobacilliorbifido bacteria. Clinical Infectious Diseases. 36: 775-780.

Brook, I. (1996): Isolation of non-sporing anaerobic rods from infections in children. J. of Medical Microbiol. 45: 21-26.

Delcenserie, V.; Bechoux, N.; China, B.; Daube, G. and Gavini, F. (2005): A PCR method for detection of Bifidobacteria in raw milk and raw milk cheese: comparison with culturebased methods. J. Microbiol. Methods. 61: $55-67$.
Gasser, F. (1994): Safety of lactic acid bacteria and their occurrence in human clinical infections. Bulletin de l'Institut Pasteur. 92: 45-67.

Gavini, F. and Beerens, H. (1999): Origin and identification of bifidobacteria strains isolated from meat and meat products. Int. J. Food Microbiol. 46: 81-85.

Gavini, F.; Cayuela, Ch.; Antoine, J.M.; Lecoq, C.; Lefebvre, B.; Membré, J.M. and Neut, Ch. (2001): Differences in the distribution of bifidobacterial and enterobacterial species in human faecalmicroflora of three different (children, adults, elderly) age groups. Microb. Ecol. Health. Dis., 13: 40-45.

Gilpin, B.; James, T.; Nourozi, F.; Saunders, D.; Scholes, P. and Savill, M. (2003): The use of chemical and molecular microbial indicators for faecal source identification. Water Sci. Technol. 47: 39-43.

Grand, M.; Küffer, M. and Baumgartner, A. (2003): Quantitative analysis and molecular identification of bifidobacteria strains in probiotic milk products. Eur. Food Res. Technol. (217): 90-92.

Green, S.L. (1978): Case report: fatal anaerobic pulmonary infection due to Bifidobacterium eriksonii. Postgraduate Medicine. 63: 187-188.

Grill, J.P.; Perrin, S. and Schneider, F. (2000): Bile salt toxicity to some bifidobacteria strains: role of conjugated bile salt hydrolase and $\mathrm{pH}$. Edge J. Microbiol. 46 (10): 878-884.

Harmsen, H.J.M.; Wildehoer, A.C.M.; Raangs, G.C.; Wagendorp, A.A.; Klijn, N.; Bindels, J.G. and Welling, G.W. (2000): Analysis of intestinal flora development in breast-fed and formulafed infants by using molecular identification and detection methods. J. Pediatr. Gastroenterol. Nutr. 30: 61-67.

Ingrassia, T.; Roques, C. and Prevots, F. (2001): Preliminary experiments for ARDRA validation on flora associated with intestinal mucosa. Lait 81: 263-280.

Kihal, M.; Prevost, H.; Lhotte, M.E.; Huang, D.Q. and Diviès, C. (1996): Instability of plasmidencoded citrate permease in Leuconostoc. J. Appl. Microbiol. 22: 219-223.

Kouamé-Sina, S.M.; Kohei, M.; Delia, G.; Marcellin D.; Bernard, T.; Georges, D. and Bassirou, B. (2011): Diversity, phylogenetic relationship and antibacterial potential of Bifidobacterium species isolated from raw milk production chain in Abidjan (Côte d'Ivoire). Afr. J. Microbiol. Res. 5 (21): 3394-3403.

Leo, M.; Gwenaelle, L. and Anne, T. (2008): Safety assessment of dairy microorganisms: Propionibacterium and Bifidobacterium. Int. J. Food Microb. 126: 316-320.

Lynch, P.; Gilpin, B.; Sinton, L. and Savill, M. (2002): The detection of Bifidobacterium adolescentis by colony hybridization as an indicator of human faecal pollution. J. Appl. Microbiol. 92: 526-533. 
Mara, D.D. and Oragui, J.I. (1983): Sorbitolfermenting bifdobacteria as specifc indicators of human faecal pollution. J. Appl. Bact., 55: 349-357.

Martineau, B. (1999): Comparison of four media for the selection of Bifidobacteria in dog fecal samples. Anaerobe. 5: 123-127.

Matsuki, T.; Watanabe, K.; Tanaka, R.; Fukuda, M. and Oyaizu, H. (1999): Distribution of Bifidobacterial species in human intestinal microflora examined with $16 \mathrm{~S}$ rRNA-genetargeted species-specific primers. Appl. Environ. Microbiol. 65: 4506-4512.

Mikkelsen, L.; Bendixen, C.; Jakobsen, M. and Jensen, B. (2003): Enumeration of Bifidobacteria in gastrointestinal samples from piglets. Appl. Environ. Microbiol. 69: 654-658.

Miyake, T.; Watanabe, K.; Watanabe, T. and Oyizu, $H$. (1998): Phylogenetic analysis of the genus Bifidobacterium and related will genera based one 16S RNA sequences. Microbiol. Immunol. 42: 661-667.

Mutai, M. and Tanaka, R. (1987): Ecology of Bifidobacterium in the human intestinal flora. Bifidobacteria Microflora. 6: 33-61.

Nebra, Y.; Bonjoch, X. and Blanch, A. (2003): Use of Bifidobacterium dentium as an indicator of the origin of fecal water pollution. Appl. Environ. Microbiol. 69: 2651-2656.

Petr, J. and Rada, V. (2001): Bifidobacteria are obligate inhabitants of the crop of adult laying hens. J. Vet. Med., B. Infect. Dis. Vet. Public Health. 48: 227-233.

Rada, V. and Petr, J. (2000): A new selective medium for the isolation of glucose nonfermenting Bifidobacteria from hen caeca. J. Microbiol. Methods. 43: 127-132.

Rasic, J.L. and Kurman, J.A. (1983): Bifidobacteria and their role. Microbiology, nutritional physiological, medical and technological aspects and bibliography. Binkauser Verlag, Basel, Boston Stuttgart.

Rhodes, M.W. and Kator, H. (1999): Sorbitolfermenting bifidobacteria as indicators of diffuse human fecal pollution in estuarine watersheds. J. Appl. Bact. 87: 528-535.

Saarela, M.; Mättö, J. and Mattila-Sandholm, T. (2002): Safety aspects of Lactobacillus and
Bifidobacterium species originating from human oro-gastrointestinal tract or from probiotic products. Microbial. Ecology in Health and Disease 14: 233-240.

Saidi, N.; Guessas, B.; Bensalah, F.; Badis, A.; Hadadji, M.; Henni, D.E.; Prevost, H. and Kihal, M. (2002): Caractérisation des bactéries lactiques isolées du lait cru de chèvre des regions arides. J. Alg. Reg. Arides: 101 -111.

Samelis, J.; Maurogenakis, F. and Metaxopoulos, J. (1994): Characterization of lactic acid bacteria isolated from naturally fermented Greek dry salami. Inter. J. Food Microbiol. 23: 179-196.

Scardovi, V. (1986): Genus Bifidobacterium. In: Bergey's Manual of Systematic Bacteriology, Vol. 2 (Eds.: Sneath, P.H.A./Mair, N.S. / Sharpe, M.E. / Holt, J.G.). Baltimore, Williams and Wilkins, 1418-1434.

Sghir, A.; Gramet, G.; Suau, A.; Rochet, V.; Pochart, P. and Dore, J. (2000): Quantification of bacterial groups within the human fecal flora by oligonucleotide probe hybridization. Appl. Environ. Microbiol. 66: 2263-2266.

Simpson, P.J.; Ross, R.P.; Fitzgerald, G.F. and Stanton, C. (2004a): Bifidobacterium psychraerophilum spp. nov. and Aeriscardovia aeriphila gen. nov., sp. nov., isolated from a porcine caecum. Int. J. Syst. Evol. Microbiol. 54: 401-406.

Simpson, P.; Fitzgerald, G.; Stanton, C. and Ross, R. (2004b): The evaluation of a mupirocin-based selective medium for the enumeration of Bifidobacteria from probiotic animal feed. J. Microbiol. Methods. 57: 9-16.

Sinton, L.; Finlay, R. and Hannah, D. (1998): Distinguishing human from animal faecal contamination in water: a review. New Zealand J. Marine and Freshwater Research. 32: 323-348.

Sutherland, R.; Boon, R.; Griffin, K.; Masters, P.; Slocombe, B. and White, A. (1985): Antibacterial activity of mupirocin (pseudomonic acid), a new antibiotic for topical use. Antimicrob. Agents Chemother. 27: 495-498.

Ventura, M.; De van Sinderen, G.F.; Fitzgerald, and Zink, R. (2004): Insights into the taxonomy, genetics and physiology of Bifidobacteria. Antoine van Leeuwenhoek. 86: 205-233. 


\section{تقييم الجودة الصحية للبن الخام اعتمادا علي تواجد ميكروب البيفيدوبكتريا كمؤشر للتلوث بالروث \\ في مدينة اسيوط تئو ميكوب \\ مروة محمد نبيل الجندي ، لمباء محمد طلعت علي}

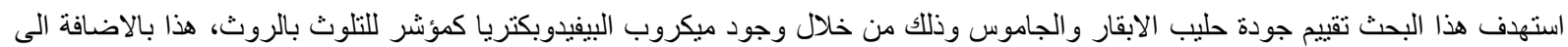

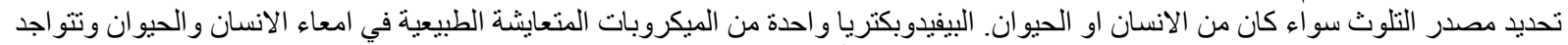

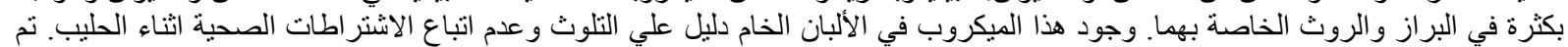

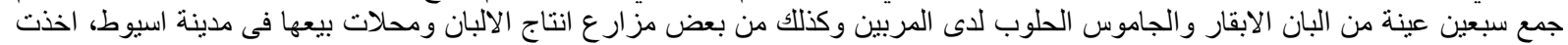

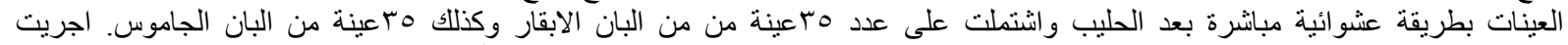

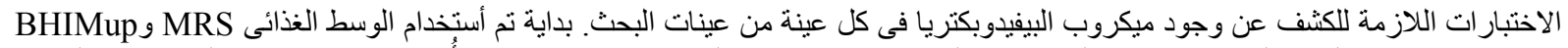

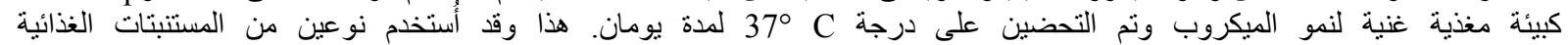

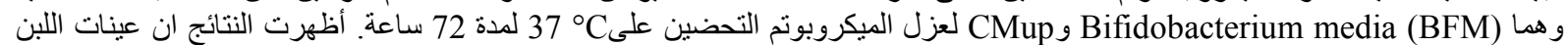

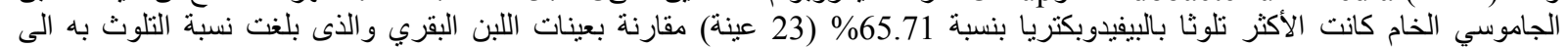

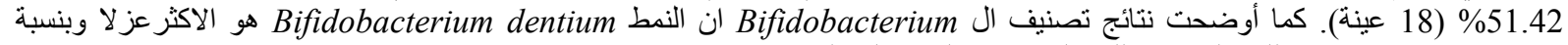

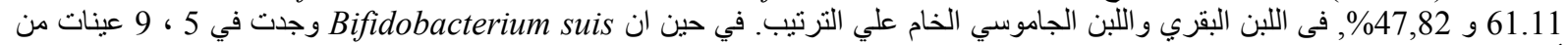

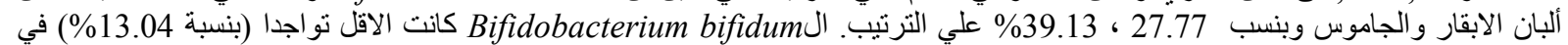

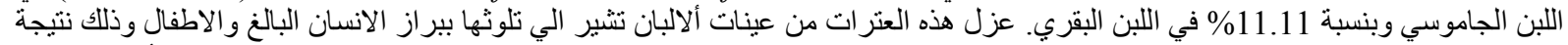

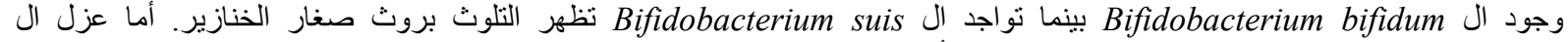

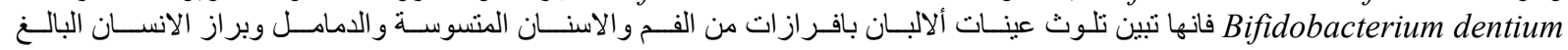
.( human dental caries; human abscesses and stooles) 